\title{
BMJ Open Mapping the evidence of intimate partner violence among women living with HIV/AIDS in sub-Saharan Africa: a scoping review
}

\author{
Mengistu Meskele (D) , ${ }^{1,2}$ Nelisiwe Khuzwayo, ${ }^{2}$ Myra Taylor (D) ${ }^{3}$
}

To cite: Meskele M, Khuzwayo N, Taylor M. Mapping the evidence of intimate partner violence among women living with HIV/ AIDS in sub-Saharan Africa: a scoping review. BMJ Open 2021;11:e041326. doi:10.1136/ bmjopen-2020-041326

- Prepublication history and additional supplemental material for this paper are available online. To view these files, please visit the journal online (http://dx.doi.org/10.1136/ bmjopen-2020-041326).

Received 05 June 2020 Revised 05 April 2021 Accepted 08 April 2021

\section{Check for updates}

C Author(s) (or their employer(s)) 2021. Re-use permitted under CC BY-NC. No commercial re-use. See rights and permissions. Published by BMJ.

${ }^{1}$ School of Public Health, Wolaita Sodo University, Wolaita Sodo, Ethiopia

${ }^{2}$ School of Nursing and Public Health, University of KwaZuluNatal College of Health Sciences, Durban, South Africa ${ }^{3}$ Public Health Medicine, University of KwaZulu-Natal College of Health Sciences, Durban, South Africa

Correspondence to Dr Mengistu Meskele; mengistumeskele@wsu.edu.et

\section{ABSTRACT}

Objectives The present study undertakes a scoping review aimed to map the evidence of intimate partner violence (IPV) against women living with HIV/AIDS in Africa. Design We used the online database to identify papers published from 1 January 2009 to 1 April 2019, from which we selected 21 articles from Uganda, Nigeria, Kenya, South Africa, Zambia, Ethiopia, Cameroon, Tanzania and Swaziland that used IPV as an outcome variable among women living with HIV/AIDS.

Data sources PubMed, MEDLINE, EBSCO host, Google Scholar.

Eligibility criteria We included women who were aged 15 years and above, living with HIV/AIDS in sub-Saharan Africa.

Data extraction and synthesis We conducted the abstract screening with two independent reviewers. We also performed full-text screening. We used the six methodological frameworks proposed by Arksey and 0'Malley. The Mixed Method Appraisal Tool was used to determine the quality of the studies. We used NVIV0 software V.12 to undertake a thematic analysis.

Results of the studies, the majority, $57.1 \%$, reported cross-sectional results. In comparison, $23.8 \%$ examined qualitative studies, $9.5 \%$ were clinical trials, $4.8 \%$ were cohort studies and the remaining $4.8 \%$ covered grey literature. This review revealed evidence of IPV experience among women with HIV/AIDS, evidence of how HIV status disclosure influences IPV, proof of the association of sociodemographic characteristics with IPV and implications for practice. Moreover, the review revealed that following the serostatus disclosure, there is evidence of heightened risk for IPV.

Conclusions This study found evidence of IPV among women living with HIV/AIDS. The HIV-positive women were at considerable risk of IPV after disclosure of their serostatus to a male partner. Therefore, further research is needed to promote action to reduce IPV among HIVpositive and HIV-negative women and to determine healthcare workers' IPV screening experience.

\section{INTRODUCTION}

Women living with HIV/AIDS who disclose their HIV serostatus are more likely to experience intimate partner violence (IPV) than women who are HIV-negative. ${ }^{1}$ Among the

\section{Strengths and limitations of this study}

- This review aimed to assess in-depth associations among women living with HIV/AIDS, and we obtained baseline evidence for future research in intimate partner violence (IPV).

- One of the limitations of this review is that it only included the literature published in the English language.

- The studies published in other languages were not included and the additional evidence of IPV among women infected with HIV/AIDS was not part of this review's assessment is also a limitation.

- We did not include all the articles in our review because some were published in journals inaccessible to us.

former, IPV and HIV/AIDS may provide overlapping, or perhaps intersecting, challenges. ${ }^{2}$ The reason that women experience this violence is that the abusers have usually been shown to want to establish and maintain power and control over another person. This is often reflected in the imbalance of power between the women and their abusers. ${ }^{3}$ IPV is defined as any behaviour within an intimate relationship that causes physical, psychological or sexual harm to those in the relationship. This also includes emotional abuse and controlling behaviours by an intimate partner. ${ }^{4}$

Worldwide, IPV is of public health and social concern. The prevalence of IPV in the WHO's different regions varies but was similar in the Eastern Mediterranean and South-East Asian regions, where IPV was reported to be $37 \%$ and $37.7 \%$, respectively, to that in subSaharan Africa (SSA), where the prevalence was $36.6 \% .^{5}$ Over a third of women in SSA reported IPV, and because this high prevalence of IPV was among both women and young girls, it is of concern. ${ }^{25}$ The harmful consequences of IPV among women and 
Box 1 The proposed scoping review following the six Arksey and 0 'Malley steps

Stage 1: formulating the study question.

Stage 2: identifying the relevant studies.

Stage 3: study selection.

Stage 4: charting the data.

Stage 5: collating, summarising and reporting.

Stage 6: consultation.

young girls are well documented and have been shown to affect their mental, sexual and reproductive health. ${ }^{5-7}$ In response to stress due to abuse, the immune system can be compromised, which later exacerbating the spread of cancer and viral infections. ${ }^{5}$ To the biological stress response, there are behavioural and other risk factors that also influence the link between IPV and adverse health outcomes. ${ }^{5}$

Studies on IPV and depression show that women who are exposed to physical violence, childhood sexual abuse, mild or severe emotional violence and high levels of spousal control are more likely to be depressed, ${ }^{6-8}$ to abuse alcohol $^{5-7}$ and give birth to babies of low birth weight. ${ }^{5-7}$ Since they may not be able to negotiate condom use, ${ }^{5-7}$ they are also at risk of sexually transmitted infections, including HIV/AIDS. ${ }^{5-79}$

The relationship between IPV and HIV/AIDS among women and young girls is a topic of intense debate within the scientific community. ${ }^{2} 10$ Some researchers consider that IPV increases women's vulnerability to HIV infection, ${ }^{15-7}$ while other researchers suggest that HIV-positive status among women may influence IPV. ${ }^{2}{ }^{11} \mathrm{~A}$ study conducted in Zimbabwe among pregnant women living with HIV/AIDS revealed an IPV prevalence of $40 \% .^{12}$ Another study in Kenya showed that after HIV-positive serostatus disclosure, one in three women experienced IPV. ${ }^{13}$ Moreover, both the combination of physical and sexual IPV (OR: 2.00; 95\% CI 1.24 to 3.22) and the experience of any type of IPV were associated with HIV/AIDS infection in women $(\mathrm{OR}=1.41 ; 95 \%$ CI 1.16 to 1.73$) .{ }^{14}$

IPV and HIV/AIDS are thus two pandemics that require integrated and collaborative interventions. The Joint United Nations Programme established new targets for the scaling up of HIV/AIDS treatment by 2030. Among its aims are to increase the number of people who know their HIV/AIDS status by $90 \%$, to increase the number of people who receive sustained antiretroviral therapy (ART) by $90 \%$ and to strive to ensure that $90 \%$ of all people who are HIV/AIDS seropositive receive ART. ${ }^{15}$ These new targets are promising, but achieving them could be compromised by women and young girls experiencing IPV. Therefore, we conducted a scoping review to systematically map the IPV research conducted among women living with HIV/AIDS to identify the existing gaps in knowledge. The information generated through this scoping review can be used by researchers, policymakers and programme developers to foster appropriate programmes and policy frameworks.

\section{METHODS}

The protocol ${ }^{16}$ of this review was published in the $B M J$ Open. Currently, the International Prospective Register of Systematic Reviews does not register a scoping review. This review is part of a large-scale study on IPV among women in Ethiopia living both with and without HIV/ AIDS. We used the six frameworks proposed by Arksey and $\mathrm{O}^{\prime}$ Malley ${ }^{17}$ : (i) identifying the research questions and defining the eligibility criteria; (ii) identifying relevant studies by conducting an extensive search; (iii) making the study selection and appraising its quality; (iv) synthesising the included studies (charting the data) and presenting the findings by using a Preferred Reporting Items for Systematic Reviews and Meta-Analyses (PRISMA) chart; (v) collating, summarising and reporting; (vi) consulting (box 1).

\section{Stage 1: identifying the research questions}

This scoping protocol is based on the following research questions:

1. Is there evidence of IPV experience among women living with HIV/AIDS in Africa?

2. Is there evidence that shows that HIV/AIDS status disclosure influences IPV among women in Africa?

3 . Is there evidence that sociodemographic characteristics are associated with IPV among women living with HIV/AIDS in Africa?

\section{Eligibility criteria}

Inclusion criteria

1. Studies with study participants aged 15 years and above.

2. Studies with evidence of IPV against women.

3. Studies with evidence about HIV-positive persons.

4. Studies on IPV over the past 10 years for the maximum amount of updated information: years of publication from 1 January 2009 to 1 April 2019.

5. Peer-reviewed literature, grey literature, government documents, policy briefs, systematic reviews and metaanalysis.

6. Studies conducted in sub-Saharan African countries (all the countries in Africa except Algeria, Djibouti, Egypt, Libya, Morocco, Somalia, Sudan and Tunisia).

\section{Exclusion criteria}

Articles published in a language other than English.

The elements of the population, concept and context criteria to map studies correctly ${ }^{18}$ (table 1 ).

\section{Stage 2: identifying the relevant studies}

We created a Google form to search the literature in which we included the topic of the study, author and date and a review questionnaire. The Google form enabled screeners to record studies for screening that have been included in the Endnote library. We inserted the keywords 


\begin{tabular}{ll}
\hline Table 1 PCC framework \\
\hline PCC & Description \\
\hline P=Population & $\begin{array}{l}\text { The population for this study were all } \\
\text { women aged } 15 \text { years and above living with } \\
\text { HIV/AIDS or receiving ART }\end{array}$ \\
C=Concept & $\begin{array}{l}\text { IPV (physical, and/or sexual and/or } \\
\text { emotional/psychological violence) or } \\
\text { domestic violence }\end{array}$ \\
C=Context & $\begin{array}{l}\text { Sub-Saharan African countries where the } \\
\text { problem of IPV mostly exists among women } \\
\text { living with HIV/AIDS }\end{array}$ \\
\hline
\end{tabular}

ART, antiretroviral therapy; IPV, intimate partner violence.

into the PubMed advanced search menu, and the results that appeared were selected and exported to Endnote.

In addition, using a comprehensive strategy, we searched for published evidence and included it in this study. A variety of literature, including peer-reviewed articles and grey literature, were retrieved. In the PubMed advanced search, we used MeSH terms such as IPV, women, HIV, Africa, domestic violence, and focused on dates of publication after 1 January 2009.

In addition to PubMed, we used MEDLINE with full text via EBSCO host, Google Scholar, Science Direct and Scopus. We found a total of 750 articles from the PubMed search and identified 128 additional records through other sources. We completed the search on 8 April 2019 (online supplemental file 1).

\section{Stage 3: study selection}

\section{Screening}

In our search strategy, we piloted to check the appropriateness of the selected electronic databases and the keywords we decided to include. The principal author conducted title screening, and two reviewers conducted the abstract screening independently. The purpose of the title screening was to assess the titles for eligibility and to remove duplicates. We created an Endnote library to which all the eligible titles were exported. We removed any duplicates before the screening of the abstract. Relevant articles based on the inclusion criteria of the scoping review were selected.

The independent reviewer abstract screening was to minimise reporting bias. ${ }^{18}$ Moreover, we undertook the full-text article screening independently, based on the eligibility criteria. We contacted the authors for the articles that were not available electronically and requested these be sent to us directly. During the full article retrieval, we used the University of KwaZulu-Natal library. When a disagreement arose between the two reviewers, a third reviewer made the decision. We presented the update of the findings by using a PRISMA chart.

\section{Quality assurance of the study}

To determine the methodological quality, we adapted and used the Mixed Methods Appraisal Tool (MMAT) 2018 version to evaluate each review. ${ }^{19}$ Additionally, we used the Preferred Reporting Items for Systematic Review and Meta-Analysis Protocols 2015 and PRISMA Extension for Scoping Reviews checklists to check whether the recommended items were included or not. ${ }^{20}{ }^{21}$ During analysis, we reviewed the checklist of the Consolidated Criteria for Reporting Qualitative Research, a 32-item checklist for interviews and focus group discussions. ${ }^{22}$

\section{Stage 4: charting the data}

We used the data charting table (table 2) to extract the necessary background information and to extract information from each selected study. We used an Excel spreadsheet for the data charting. This form highlighted essential ideas regarding the variables from the background and included the research questions which were addressed by the variables and the themes. Two reviewers jointly developed the data charting form to decide which variables to extract, which they charted independently. We continuously updated the data charting form during the duration of the study.

\section{Data items}

We abstracted data on the article characteristics (eg, year, country of origin), aim of the study, IPV and population (HIV-positive women), sample size, age group, and the study design.

\section{Stage 5: collating, summarising and reporting the result}

We undertook qualitative data analyses using NVIVO software V.12 to collate, summarise and report the results. First, the researchers read and reread the articles thoroughly, noting down the initial ideas to find codes. The notable features of the data across the entire article were systematically coded, and data relevant to each code was collated. We then developed the codes into potential themes and finally defined and named the themes and produced the report. ${ }^{23}$ We used the description of the coding tree and thematic content analysis to analyse the data. We extracted and coded the data that were related to the IPV experience among HIV-positive women, identified the emerging themes and then coded the data according to these themes. The analysis process used the following steps: (i) coding data from the selected articles; (ii) categorising the codes into themes; (iii) displaying the data; (iv) identifying key patterns in the data and the subthemes; (v) summarising and synthesising.

\section{Stage 6: consultation}

We held consultations with the stakeholders, such as policymakers (two), clinicians (three), patients (five) and families (two), in addition to other appropriate groups who researched IPV, in order to obtain more references and to provide insights on what the literature failed to highlight. ${ }^{24}$ Moreover, these consultations helped in mapping the evidence of the existence of physical, emotional and sexual violence among HIV infected women. The talks helped to gain further insight into IPV. 
Table 2 Data charting table

\begin{tabular}{|c|c|c|c|c|c|c|}
\hline Author & Country & Study aim & Population & $\begin{array}{l}\text { Sample } \\
\text { Size }\end{array}$ & $\begin{array}{l}\text { Age group } \\
\text { (years) }\end{array}$ & Study design \\
\hline Ashaba et $a l^{25}$ & Uganda & $\begin{array}{l}\text { To explore psychosocial } \\
\text { challenges experienced by } \\
\text { women living with HIV }\end{array}$ & Women & 20 & $22-40$ & Qualitative \\
\hline Bernstein et $a l^{26}$ & South Africa & $\begin{array}{l}\text { To assess the prevalence } \\
\text { and correlates of IPV } \\
\text { among HIV-infected } \\
\text { pregnant women }\end{array}$ & Women & 623 & $18-44$ & Cross-sectional \\
\hline $\begin{array}{l}\text { Lauren and Van } \\
\mathrm{Zyl}^{27}\end{array}$ & South Africa & $\begin{array}{l}\text { To measure how IPV } \\
\text { impacts women's safety } \\
\text { following mobile HCT } \\
\text { diagnosis }\end{array}$ & Women & 255 & $18+$ & Clinical trial \\
\hline Colombini et $a l^{13}$ & Kenya & $\begin{array}{l}\text { To explore women's } \\
\text { experiences of IPV risks } \\
\text { following disclosure to their } \\
\text { partner }\end{array}$ & Women & 30 & $15-49$ & Qualitative \\
\hline Emusu et $a l^{29}$ & Uganda & $\begin{array}{l}\text { To explore the experiences } \\
\text { of sexual violence among } \\
\text { women in HIV-discordant } \\
\text { unions }\end{array}$ & Women & 26 & $\begin{array}{l}\text { Not } \\
\text { mentioned }\end{array}$ & Qualitative \\
\hline Ezeanochie et $a l^{30}$ & Nigeria & $\begin{array}{l}\text { To evaluate the prevalence } \\
\text { and correlates of IPV } \\
\text { among HIV-positive women }\end{array}$ & Women & 305 & $21-43$ & Cross-sectional \\
\hline Ezechi et $a l^{31}$ & Nigeria & $\begin{array}{l}\text { To determine the } \\
\text { prevalence, types and } \\
\text { correlates of IPV }\end{array}$ & Women & 652 & $<20-\geq 40$ & Cross-sectional \\
\hline $\begin{array}{l}\text { Hampanda and } \\
\text { Rael }^{34}\end{array}$ & Zambia & $\begin{array}{l}\text { To advance the current } \\
\text { understanding of the } \\
\text { relationship between IPV } \\
\text { against women and their } \\
\text { HIV status disclosure } \\
\text { behaviours }\end{array}$ & Women & 320 & $18+$ & Cross-sectional \\
\hline Iliyasu et $a l^{35}$ & $\begin{array}{l}\text { Northern } \\
\text { Nigeria }\end{array}$ & $\begin{array}{l}\text { To assess prevalence and } \\
\text { risk factors of domestic } \\
\text { violence among HIV- } \\
\text { positive women }\end{array}$ & Women & 300 & $18-70$ & $\begin{array}{l}\text { Descriptive and } \\
\text { cross-sectional }\end{array}$ \\
\hline $\begin{array}{l}\text { Malaju and } \\
\text { Alene }^{36}\end{array}$ & Ethiopia & $\begin{array}{l}\text { To assess women's } \\
\text { expectations of their } \\
\text { partner's violence on the } \\
\text { disclosure of the HIV test }\end{array}$ & Women & 400 & $15-49$ & Cross-sectional \\
\hline Mulrenan et $a l^{37}$ & Swaziland & $\begin{array}{l}\text { To explore the risks of } \\
\text { experiencing IPV after HIV } \\
\text { infection among women } \\
\text { with HIV }\end{array}$ & Women & 19 & $18-44$ & Qualitative \\
\hline
\end{tabular}


Table 2 Continued

\begin{tabular}{|c|c|c|c|c|c|c|}
\hline Author & Country & Study aim & Population & $\begin{array}{l}\text { Sample } \\
\text { Size }\end{array}$ & $\begin{array}{l}\text { Age group } \\
\text { (years) }\end{array}$ & Study design \\
\hline Olowookere et $a l^{38}$ & Nigeria & $\begin{array}{l}\text { To assess the prevalence } \\
\text { and correlates of IPV } \\
\text { among women living with } \\
\text { HIV/AIDS in an antiretroviral } \\
\text { clinic in Nigeria }\end{array}$ & Women & 360 & $18+$ & Cross-sectional \\
\hline Osinde et $a l^{40}$ & Uganda & $\begin{array}{l}\text { To measure the prevalence } \\
\text { and factors associated with } \\
\text { IPV among HIV-infected } \\
\text { women }\end{array}$ & Women & 317 & $15+$ & Cross-sectional \\
\hline Young et $a l^{42}$ & Uganda & $\begin{array}{l}\text { To examine physical and } \\
\text { sexual IPV prevalence and } \\
\text { correlates among WLWH in } \\
\text { Uganda }\end{array}$ & Women & 455 & $18+$ & Cohort \\
\hline $\begin{array}{l}\text { United Nations } \\
\text { Educational, } \\
\text { Scientific } \\
\text { and Cultural } \\
\text { Organization }{ }^{44}\end{array}$ & Tanzania & $\begin{array}{l}\text { To discuss the links } \\
\text { between gender-based } \\
\text { violence and HIV and AIDS } \\
\text { in conflict and post-conflict } \\
\text { situations in the Great } \\
\text { Lakes Region }\end{array}$ & Women & $\mathrm{N} / \mathrm{A}$ & $\mathrm{N} / \mathrm{A}$ & Workshop report \\
\hline
\end{tabular}

ART, antiretroviral therapy; HCT, HIV Counseling and Testing; IPV, intimate partner violence; SV, Sexual Violence; WLWH, Women Living With HIV.

\section{RESULTS}

\section{Screening results}

We found 750 articles in the original data search. A total of 159 publications remained after we removed duplicates and other unrelated topics. A 136 articles were excluded, which did not meet our inclusion criteria, and 23 items were included for full-text screening. After the full-article screening, we excluded two studies, providing reasons for this, and a final 21 articles remained from which to extract data (figure 1).

\section{Characteristics of the included studies}

Out of the 21 included studies, 20 were published in peer-reviewed journals, ${ }^{13}$ 25-43 while the remaining one was categorised as grey literature. ${ }^{44}$ From the included studies, 12 were quantitative and cross-sectional in nature, ${ }^{2628}$ 30-36 3840415 were qualitative, ${ }^{13262937} 2$ was a clinical trial, ${ }^{2743} 1$ was a cohort design ${ }^{42}$ and the remaining one was grey literature (a conference discussion report) ${ }^{44}$ (figure 2).
Out of the 21 studies, 5 were conducted in Uganda, 25282940424 in Nigeria, ${ }^{30} 3135363$ in Kenya, ${ }^{13} 3941$ 2 in South Africa, ${ }^{26} 272$ in Zambia, ${ }^{33} 341$ in Ethiopia, ${ }^{36} 1$ in Cameroon, ${ }^{32} 1$ in Tanzania ${ }^{44}$ and the remaining 1 in Swaziland $^{37}$ (figure 3).

\section{Study findings}

Four themes emerged from the identified studies: evidence of IPV experience among women with HIV/ AIDS, evidence of HIV/AIDS status disclosure influencing IPV, evidence of the association of sociodemographic characteristics with IPV and implications for future practice.

\section{Evidence of IPV experience among women with HIV/AIDS}

We found evidence of IPV experience from almost all of the 21 included studies in the 11 countries in the SubSaharan African region. ${ }^{13}$ 25-44 The prevalence of IPV varied among countries; we identified the highest prevalence of IPV in South Africa $(67.3 \%)^{27}$ and the lowest 


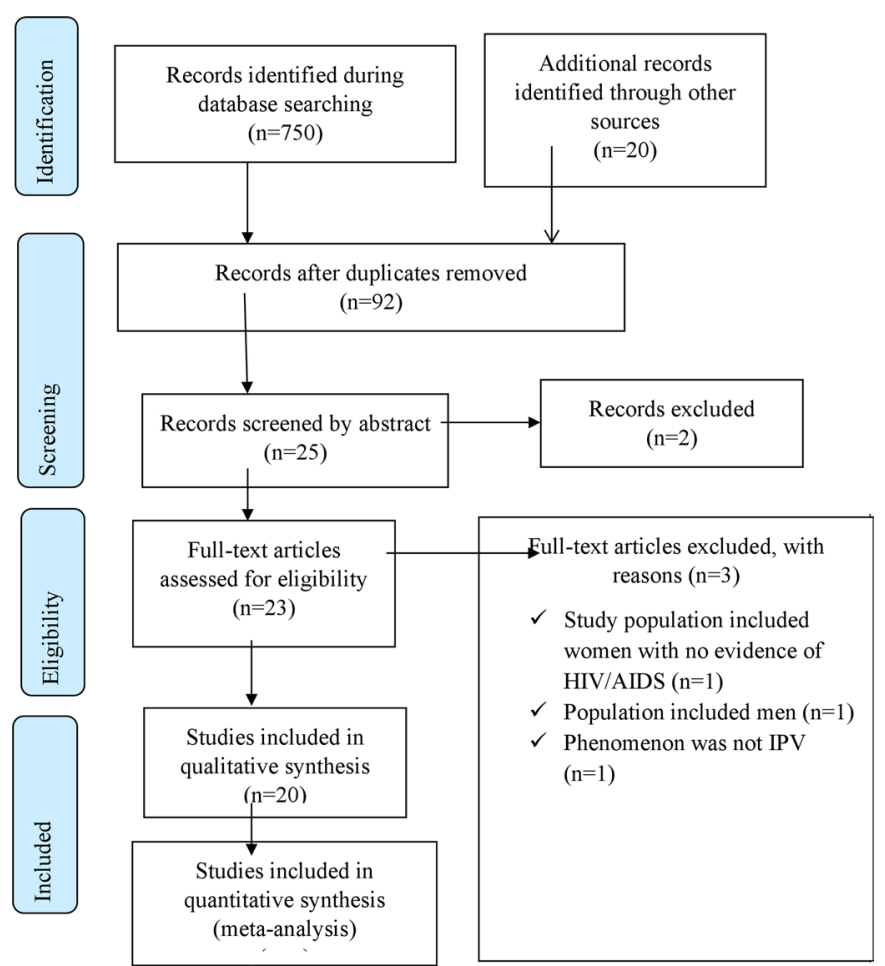

Figure 1 The Preferred Reporting Items for Systematic Reviews and Meta-Analyses 2009 flow diagram. Source: PRISMA Group: doi: 10.1371/journal.pmed.1000097. ${ }^{20}$

prevalence in Kenya $(14.6 \%) .^{41}$ IPV was also identified in Nigeria $(65.8 \%),{ }^{31}$ in South Africa, overall, 56.3\% reported having experienced either psychological or physical IPV, ${ }^{43}$ Uganda $(29 \%),{ }^{42}$ another study in South Africa, $(21 \%),{ }^{26}$ Nigeria, $(23.6 \%),{ }^{38}$ Kenya, nearly onethird of women in the study, ${ }^{13}$ Cameroon $(23 \%),{ }^{32}$ Nigeria $(22.1 \%)^{35}$ and Uganda $(29.3 \%) .{ }^{40}$ On average, one-third (30.2\%) of HIV-positive women experienced IPV among the included studies. Psychological, emotional or verbal abuse was the most common form of violence reported among HIV-positive women and ranged from $12.1 \%$ to $51.7 \% .{ }^{30-32} 3840$ One study showed that physical violence had a more pronounced effect on status disclosure than sexual or emotional violence. ${ }^{34}$ Sexual violence was found to be the least common type of abuse among HIV-positive women, ranging from $2 \%$ to $44.8 \% .^{26313238}$

Three studies showed evidence of further abuse following IPV, such as the difficulty of engaging in HIV/ AIDS care, interruption of ART adherence, partner stigma and abuse, and financial withdrawal. ${ }^{1325} 32$ There was also evidence showing that physical weakness, economic and social dependence on a partner and alcohol abuse by a male partner were the leading causes of IPV. ${ }^{29} 44$

\section{Evidence of HIV/AIDS status disclosure influencing IPV}

Evidence of IPV after HIV/AIDS status disclosure was reported from six studies. ${ }^{31}{ }^{34-38}$ Following the serodisclosure, there was evidence of heightened risk for IPV, stigma, abuse, marriage disruption and financial withdrawal. ${ }^{132531323536}$ Evidence from one study showed about $74 \%$ of abuse coming after HIV/AIDS status disclosure. ${ }^{31}$ However, some studies found that sero-concordance is protective of emotional or verbal abuse. ${ }^{13}$ Women who had their own income, those who did not have a stigmatising attitude towards people living with HIV/AIDS, those who had attained secondary level education and above, those with a positive attitude towards counsellors, and those able to access health facilities were all associated with positive partner reaction. ${ }^{36}$ On the other hand, having an HIV-negative spouse and disclosure of HIV/ AIDS status was associated with abuse. ${ }^{31}$

Studies also explored the expectation of adverse reactions related to HIV/AIDS in the community, including gossip and discrimination. ${ }^{25}{ }^{36}$ Evidence even existed that some women did not disclose their HIV/AIDS status because of expected fear of rejection, abuse and anticipated loss of trust from their partner. ${ }^{25} 3144$ For instance,

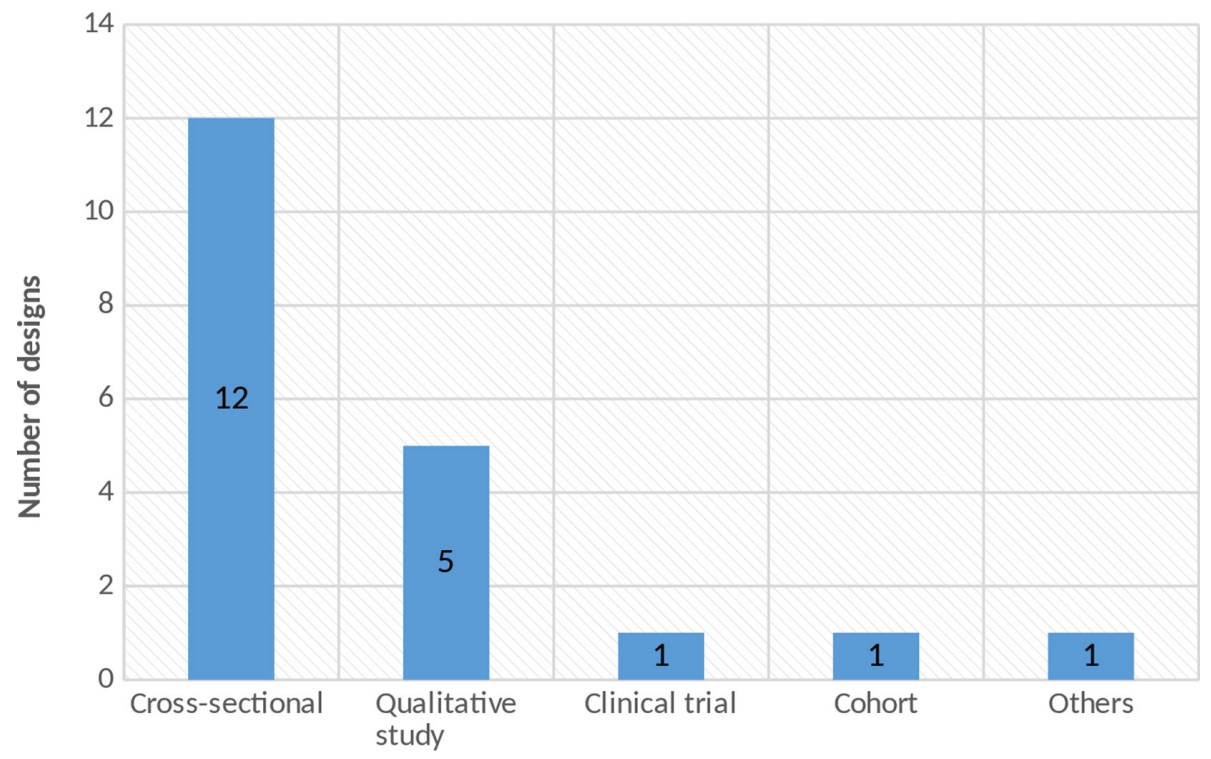

Figure 2 Distribution of study designs used in the study $(n=20)$. 


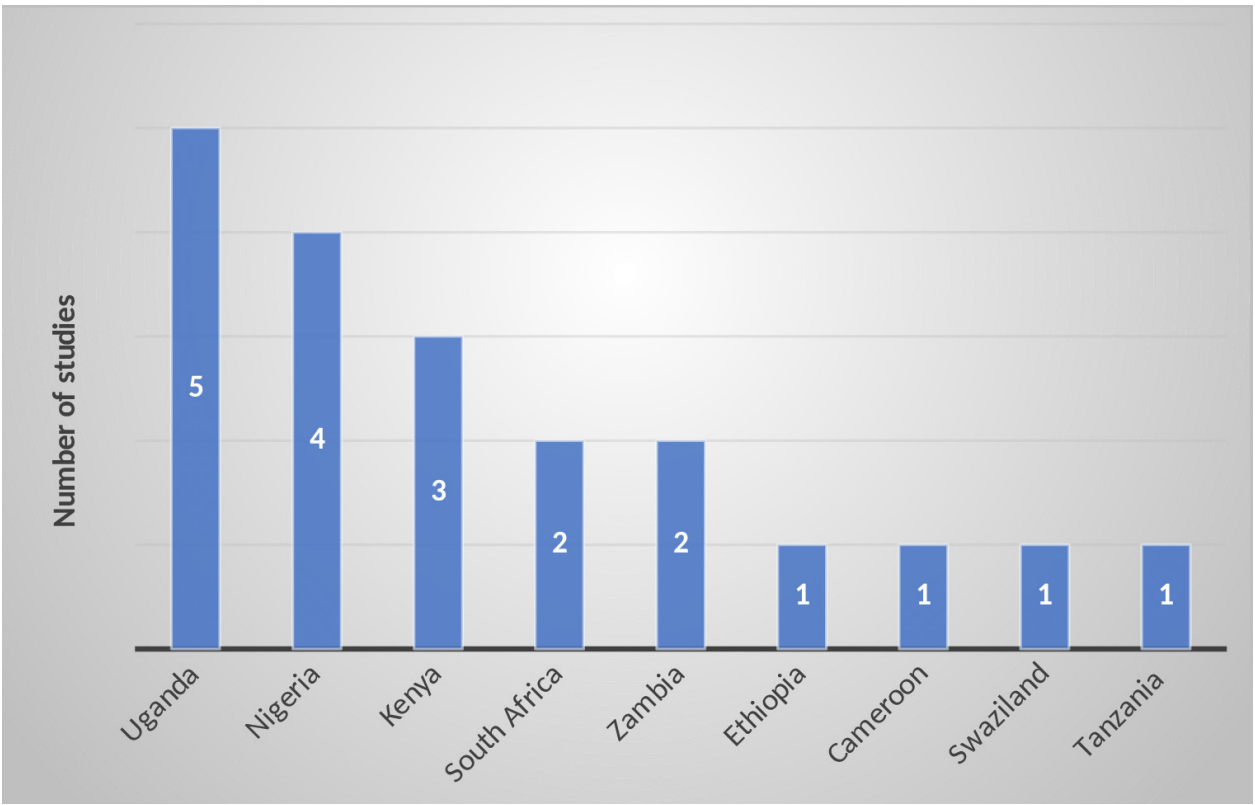

Figure 3 Distribution of countries represented in the included studies $(n=20)$.

studies showed that some women kept their HIV serostatus a secret to prevent an adverse reaction. ${ }^{25} 44$ One study also presented evidence of early mixed feeding following the disclosure of an HIV-positive status. ${ }^{33}$ Findings show that physical violence is the most prevalent form of IPV that occurs after status disclosure rather than sexual abuse. ${ }^{34}$

\section{Evidence of the association of sociodemographic characteristics with IPV}

We found evidence of sociodemographic characteristics which were associated with IPV in four studies. ${ }^{35} 384042$ One study identified that older age groups of women, those $>40$ years, were at risk for IPV. ${ }^{35}$ Contrary to this, a study in Uganda showed that being older was associated with a lower risk for IPV. ${ }^{42}$ Similarly, one study in Nigeria showed that younger partners (20-39 years) were more at risk for IPV. ${ }^{38}$

A study from Nigeria showed that multiparity, being a respondent with an HIV-positive child, and marital status (divorced women) were associated with IPV. ${ }^{35}$ However, a study in Uganda showed that being married was associated with a higher risk of IPV. ${ }^{42}$

Two studies revealed that non-formal education of husbands (ie, lack of education) was associated with IPV. $^{30}{ }^{35}$ Contrary to this, a study in rural Uganda showed that there was a significant, but inverse, the association between educational level and physical partner violence. ${ }^{40}$ There was also an inverse association between the educational level of the respondent and sexual/psychological abuse, as well as psychological/sexual violence. ${ }^{40}$

Only one study from Uganda reported that a higher household asset index score was protective from IPV. ${ }^{42}$ The sociodemographic factor of alcohol abuse by male partners was an essential factor associated with IPV among HIV-positive women. ${ }^{29} 3841$ Additionally, IPV was associated with the experience of violence before women had an HIV-positive diagnosis. ${ }^{30}$ Moreover, a Ugandan study reported that the use of ART was associated with an increased prevalence of IPV. ${ }^{40}$ One study result also showed that women experiencing controlling behaviour by the index partner was associated with IPV. ${ }^{41}$

\section{Implications for future practice}

Evidence from four studies indicated that the prevention of IPV is through the integration of partner violence identification and care into other healthcare services (sexual and reproductive services and services such as HIV testing and counselling). ${ }^{13283034}$ A study in Uganda recommended the integration of various stakeholders, including partners, family, policymakers, community members and funders and programme implementers who could work together to prevent IPV. ${ }^{25}$

Healthcare workers (HCWs) should ensure safe disclosure to avoid post-disclosure abuse. Safe disclosure, including couple counselling, mutual disclosure between partners, separate counselling sessions for men and facilitated disclosure were recommendations. ${ }^{132537}$ A study also reported that HIV/AIDS counsellors should evaluate the advantages and disadvantages of status disclosure among women. ${ }^{34}$ Furthermore, a Zambian study indicated that IPV prevention required training counsellors to facilitate discussions with women about IPV. ${ }^{34}$ Moreover, evidence from two studies showed the importance of ensuring that women's decisions to disclose their HIV serostatus are fully informed and voluntary. ${ }^{13} 34$ Evidence from five studies reported that routine screening for IPV to identify abused women during HIV/AIDS care services is necessary. $^{26} 30324042$ Furthermore, evidence from a Ugandan study also highlighted that HCWs should inform HIVdiscordant couples appropriately on their reproductive options and referral systems and link couples with counselling services on sexual violence. ${ }^{29}$ 
A study also proposed a way forward by improving public awareness and family counselling as a strategy of IPV prevention. ${ }^{37}$ Four studies recommended that promoting gender equity, empowering women economically, as well as promoting positive masculinities that support and protect women are measures to prevent IPV. ${ }^{25} 28{ }^{31}$ Moreover, two studies reported the involvement of men in programmes of IPV prevention..$^{25} 37$

\section{DISCUSSION}

This scoping review was aimed at mapping the evidence of IPV against women living with HIV/AIDS in SSA. It revealed evidence of IPV experience among women with HIV/AIDS, how HIV/AIDS status disclosure influences its prevalence, and proof of the association of sociodemographic characteristics with IPV. The implications for future practice and recommendations were also made evident.

The experience of IPV varies among SSA countries. On average, $30.2 \%$ of HIV-positive women had experienced IPV. This overall finding corresponds to the results of Ugandan and Kenyan studies. ${ }^{13} 4042$ Of the types of IPV, emotional abuse was the most common form of violence reported among HIV-positive women ${ }^{30-32} 38$ 40; sexual violence was found to be the least common type of abuse among HIV-positive women. ${ }^{26} 313238$ As a result of this type of violence, women delayed accessing ART for fear of further violence, experienced denial of healthcare or discrimination in healthcare settings, employment, education, housing and enforced HIV testing. ${ }^{6} 74$ In light of these findings, studies highlighted strategies to protect women from IPV by the integration of violence identification and care into other healthcare services (sexual, reproductive and HIV/AIDS-related services such as HIV testing and counselling services). ${ }^{13} 283034$ It was suggested that the integration of the family, policymakers, community members, as well as funders and programme implementers in gender-based violence prevention programmes, were a way forward.$^{25}$

The WHO data in 2018 showed that 25.7 million people are living with HIV/AIDS in Africa, ${ }^{45}$ indicating that HIV/AIDS continues to be one of the significant causes of disease burden in SSA, ${ }^{45} 46$ causing substantial health problems in the region. However, studies have highlighted that the effect of the HIV/AIDS epidemic varies in different countries of SSA. ${ }^{46}$ Significant to this study, research in Africa has also shown that there is a strong association between HIV infection and IPV. ${ }^{47}$ This relationship between the two health problems is complex and iterative ${ }^{48}$; because of this, countries with a high HIV/AIDS prevalence, for instance, South Africa and Nigeria, account for a high prevalence of violence $(67.3 \%)^{27}$ and $(65.8 \%),{ }^{31}$ respectively. The studies in this review included countries with a varying range of HIV/AIDS prevalence; as reported in 2016, these were Swaziland (27.2\%), South Africa (18.9\%), Zambia (12.4\%), Uganda (6.5\%), Kenya (5.4\%), Tanzania
$(4.7 \%)$, Cameroon $(3.8 \%)$, Nigeria $(2.9 \%)$ and Ethiopia $(1.1 \%) .{ }^{49}$ Moreover, IPV can itself also be both a risk factor for and a consequence of HIV/AIDS. ${ }^{50}$ Therefore, IPV needs safe monitoring, screening and intervention among HIV-positive women in healthcare settings. ${ }^{48}$

Evidence of IPV following HIV/AIDS status disclosure was found in nine studies reviewed..$^{1325313234-38}$ If our study had searched only for the effect of HIV/AIDS disclosure without IPV, more evidence of the consequences of HIV/AIDS status disclosure could have come to light. Moreover, stigma, abuse, marriage disruption and financial withdrawal were evident consequences of HIV test result disclosure. ${ }^{132531323536}$ Therefore, there is a need for safe disclosure such as couple counselling, mutual disclosure between partners, separate counselling sessions for men and facilitated disclosure. ${ }^{13} 2537$ One study also reported that HIV/AIDS counsellors should evaluate the advantages and disadvantages of status disclosure among women. ${ }^{34}$ The Zambian study suggested training counsellors to facilitate discussions with women about IPV. ${ }^{34}$ Moreover, evidence from two studies showed that ensuring women's fully informed and voluntary decision making to disclose their HIV/ AIDS serostatus is required..$^{13} 34$

A study in Uganda showed that the sociodemographic status of being married was associated with a higher risk of IPV. ${ }^{20}$ Another type of marital status, such as being divorced, was also associated with IPV in another context. $^{12}$ Hence, the prevention strategy for IPV should be emphasised for both married and divorced women. Age could also be a risk factor, depending on the country. A study in Zimbabwe identified that older women, $>40$ years, were at increased risk for IPV. ${ }^{12}$ Contrary to this, a study in Uganda showed that older age represented a lower risk for IPV.$^{20}$ Corresponding with this, a survey in Nigeria showed that younger partners (20-39 years) were at increased risk of IPV. ${ }^{15}$ However, from these findings, we realised that violence could affect all age groups; hence, the importance of improving public awareness and providing family counselling as a strategy for IPV prevention. ${ }^{14}$

Women who are living with HIV/AIDS not only experienced with IPV but also other type of violence/ stigma/discriminations. A study in South Africa showed that higher levels of depressive symptoms and greater perceived stigma were associated with physical and psychological IPV. ${ }^{43}$ It also showed that psychological IPV and physical IPV were also individually associated with high perceived stigma and higher levels of depressive symptoms. ${ }^{43}$

Studies revealed that other sociodemographic aspects, such as higher household asset value were protective against IPV. ${ }^{42}$ To this end, promoting gender equity, and empowering women economically, as well as promoting positive masculinities that support and protect women should be considered to protect against IPV. 253741 Concerned bodies are also aware that 
traditional masculine norms, for instance, aggressiveness and male suppression of emotional vulnerability, can lead to physical violence. ${ }^{51}$ Moreover, a male partner's heavy drinking and aggressive behaviour, that men believe to be an accepted norm of masculinity lead to violence. ${ }^{52}$ Hence, wise disclosure of HIV/AIDS status assisted by HCWs, mutual disclosure and involving men in programmes for IPV prevention is advisable.

Health systems should address violence because of its significantly harmful effects on women's health and well-being, including their mental, sexual and reproductive health. ${ }^{53}$ IPV seems to be a preventable health problem. Thus, the health system needs to develop a response that can provide women with a multisectoral and women-centred response providing privacy, confidentiality and accountability, empowerment of women's decision making and immediate assistance in a holistic way. ${ }^{53}$

\section{Strengths and limitations}

We used an approved MMAT to check the quality of appraisal of the included studies. We also used public health and social science databases for title screening. By doing so, we obtained all relevant published studies; however, we could have found additional pertinent articles if other bibliographical databases had been searched. Other terms, rather than the keywords we searched, could have existed in a different database. In our search, we included articles published in the English language only; therefore, we may have missed critical points published in studies presented in another language. Furthermore, this scoping review was a huge undertaking, and it only includes results up to the date of 10 April 2019.

\section{CONCLUSION}

Overall, this scoping review provides a summary of the existing literature showing the evidence of IPV experiences among women with HIV/AIDS. We found evidence of IPV experience from almost all of the studies included. On average, one-third (30.2\%) of HIV-positive women experienced IPV among the included studies. Psychological, emotional or verbal abuse was the most common form of violence reported among HIV-positive women. Furthermore, two other relevant categories of evidence reviewed are the negative influence of HIV/AIDS status disclosure on IPV and the association of sociodemographic characteristics with IPV and what the resulting implications are for practice. Psychological and emotional abuse were the most common form of violence reported. Sexual violence was found to be the least common type among HIV-positive women. The review showed the difficulty of women who experienced IPV in engaging in HIV/ AIDS care, the interruption of their ART treatment, and that stigma, abuse and financial withdrawal were some of the consequences that followed from IPV. As this review has shown, IPV was associated with HIV/AIDS status disclosure and having an HIV-negative spouse was a risk factor for IPV. In particular, there is evidence of a heightened risk for partner violence, shame, abuse, marriage disruption and financial withdrawal following serostatus disclosure.

Therefore, the review highlighted the need for strategies such as the integration of IPV screening and care into other healthcare services (sexual, reproductive and HIV/AIDS services). Moreover, safe disclosure such as couple counselling, mutual disclosure between partners, separate counselling sessions for men and facilitated disclosure is vital. The review has also emphasised routine screening for IPV to identify abused women attending HIV/AIDS care services. Most importantly, there is a need for further research among special population groups and on health systems barriers to screening for IPV and for a focus on how victims are treated.

\section{Recommendations for future research}

For future research, we suggest investigating the differences and similarities of the IPV experiences for women living with or without HIV/AIDS and the associated factors in the different regions of the various countries in SSA. The lived experience of women, both living with and without HIV/AIDS, and the HCW's experience of IPV screening and its barriers still need to be further studied.

Acknowledgements We would like to acknowledge the UKZN Systematic Review Support Service at the University of KwaZulu-Natal, South Africa, for their support through the training workshop and assistance in protocol development for the review. We would also like to extend our gratitude to the School of Nursing and Public Health, College of Health Science, University of KwaZulu-Natal, for all their assistance and help.

Contributors MM: conceived the topic and drafted the study as part of his $\mathrm{PhD}$ study; he was involved in the design and analysis. NK and MT: supervised and guided the review, engaged in the design, analysis and revisiting of the manuscript critically for relevant intellectual content. All three authors read and approved the final manuscript. MM, NK and MT agreed to be accountable for all aspects of the work.

Funding This study is part of a more extensive PhD study funded by the University of KwaZulu-Natal (UKZN).

Competing interests None declared.

Patient consent for publication Not required.

Provenance and peer review Not commissioned; externally peer reviewed.

Data availability statement Data are available upon reasonable request. Data are available up on reasonable request for all interested researcher.

Supplemental material This content has been supplied by the author(s). It has not been vetted by BMJ Publishing Group Limited (BMJ) and may not have been peer-reviewed. Any opinions or recommendations discussed are solely those of the author(s) and are not endorsed by BMJ. BMJ disclaims all liability and responsibility arising from any reliance placed on the content. Where the content includes any translated material, BMJ does not warrant the accuracy and reliability of the translations (including but not limited to local regulations, clinical guidelines, terminology, drug names and drug dosages), and is not responsible for any error and/or omissions arising from translation and adaptation or otherwise.

Open access This is an open access article distributed in accordance with the Creative Commons Attribution Non Commercial (CC BY-NC 4.0) license, which permits others to distribute, remix, adapt, build upon this work non-commercially, 
and license their derivative works on different terms, provided the original work is properly cited, appropriate credit is given, any changes made indicated, and the use is non-commercial. See: http://creativecommons.org/licenses/by-nc/4.0/.

\section{ORCID iDs}

Mengistu Meskele http://orcid.org/0000-0001-6157-4591

Myra Taylor http://orcid.org/0000-0003-3087-2240

\section{REFERENCES}

1 Abdool Karim Q, Baxter C. The dual burden of gender-based violence and HIV in adolescent girls and young women in South Africa. S Afr Med J 2016;106:1151-3.

2 The White House Washington Working Group. Addressing the intersection of HIV/AIDS, violence against women and girls, and gender-related health disparities. Washington, 2013. Available: www. hoccprograms.org/vaw-hiv_working_group_report_final_-_9-6--2013. pdf [Accessed 13 Jul 2018].

3 Government of Newfoundland and Labrador. Violence prevention initiative: defining violence and abuse. Available: https://www.gov.nl. ca/VPI/types/ [Accessed 13 Jul 2018].

4 WHO. Understanding and addressing violence against women: intimate partner violence, 2012. Available: https://apps.who.int/ iris/bitstream/handle/10665/77432/WHO_RHR_12.36_eng.pdf; jsessionid=4769C7FB9DE4C25AE8C0EFCCC68907DE? sequence $=1$ [Accessed 04 Apr 2019].

5 WHO. Global and regional estimates of violence against women: prevalence and health effects of intimate partner violence and nonpartner sexual violence. World Health organization, 2013. Available: https://www.who.int/reproductivehealth/publications/violence/ 9789241564625/en/ [Accessed 13 Jul 2018].

6 WHO. Violence against women and HIV/AIDS: critical Intersections intimate partner violence and HIV/AIDS. A UNAIDS initiative the global coalition on women and AIDS, 2009. Available: https://npin. cdc.gov/publication/intersection-intimate-partner-violence-and-hivwomen. [Accessed $13 \mathrm{Jul} 2018$ ].

7 CDC. Intersection of intimate partner violence and HIV in women, 2014. Available: https://npin.cdc.gov/publication/intersectionintimate-partner-violence-and-HIV-women [Accessed 13 Jul 2018].

8 Deyessa N, Berhane Y, Alem A, et al. Intimate partner violence and depression among women in rural Ethiopia: a cross-sectional study. Clin Pract Epidemiol Ment Health 2009;5:8

9 El-Bassel N, Gilbert L, Krishnan S, et al. Partner violence and sexual HIV-risk behaviors among women in an inner-city emergency department. Violence Vict 1998;13:377-93.

10 Durevall D, Lindskog A. Intimate partner violence and HIV in ten sub-Saharan African countries: what do the demographic and health surveys tell us? Lancet Glob Health 2015;3:e34-43.

11 Gielen AC, McDonnell KA, Burke JG, et al. Women's lives after an HIV-positive diagnosis: disclosure and violence. Matern Child Health J 2000;4:111-20.

12 Shamu S, Zarowsky C, Shefer T, et al. Intimate partner violence after disclosure of HIV test results among pregnant women in Harare, Zimbabwe. PLoS One 2014;9:e109447.

13 Colombini $\mathrm{M}$, James $\mathrm{C}$, Ndwiga $\mathrm{C}$, et al. The risks of partner violence following HIV status disclosure, and health service responses: narratives of women attending reproductive health services in Kenya. $J$ Int AIDS Soc 2016;19:20766.

$14 \mathrm{Li} \mathrm{Y,} \mathrm{Marshall} \mathrm{CM,} \mathrm{Rees} \mathrm{HC,} \mathrm{et} \mathrm{al.} \mathrm{Intimate} \mathrm{partner} \mathrm{violence} \mathrm{and} \mathrm{HIV}$ infection among women: a systematic review and meta-analysis. J Int AIDS Soc 2014;17:18845.

15 UNAIDS. Joint United nations programme on HIV/AIDS. 90-90-90 an ambitious treatment target to help end the AIDS epidemic. Available: https://www.unaids.org/sites/default/files/media_asset/90-90-90_en. pdf [Accessed 28 Jun 2019].

16 Meskele M, Khuzwayo N, Taylor M. Mapping the evidence of intimate partner violence among women living with HIV/AIDS in Africa: a scoping review protocol. BMJ Open 2019;9:e029284.

17 Arksey H, O'Malley L. Scoping studies: towards a methodological framework. Int J Soc Res Methodol 2005;8:19-32.

18 Joanna Briggs Institute. Joanna Briggs Institute reviewers' manual: 2015 edition / supplement. The Joanna Briggs Institute, 2015. Available: http://joannabriggs.org/assets/docs/sumari/ReviewersManual_Methodology-for-JBI-Scoping-Reviews_2015_v1.pdf [Accessed 01 Aug 2019].

19 Quan N, Pierre P, Sergi F. Mixed methods appraisal tool (MMAT) version 2018. in family medicine mu, Canada, editor, 2018. Available: http://mixedmethodsappraisaltoolpublic.pbworks.com/w/file/fetch/ 127916259/MMAT_2018_criteria-manual_2018-08-01_ENG.pdf [Accessed 01 Aug 2019].
20 Moher D, Liberati A, Tetzlaff J, et al. Preferred reporting items for systematic reviews and meta-analyses: the PRISMA statement. PLoS Med 2009;6:e1000097.

21 Tricco AC, Lillie E, Zarin W, et al. PRISMA extension for scoping reviews (PRISMA-ScR): checklist and explanation. Ann Intern Med 2018;169:467-73.

22 Tong A, Sainsbury P, Craig J. Consolidated criteria for reporting qualitative research (COREQ): a 32-item checklist for interviews and focus groups. Int J Qual Health Care 2007;19:349-57.

23 Braun V, Clarke V. Using thematic analysis in psychology. Qual Res Psychol 2006;3:77-101.

24 Dijkers M. What is a scoping review? 2015. Available: http://ktdrr.org/ products/update/v4n1/ [Accessed 13 Jul 2018].

25 Ashaba S, Kaida A, Coleman JN, et al. Psychosocial challenges facing women living with HIV during the perinatal period in rural Uganda. PLoS One 2017;12:e0176256.

26 Bernstein M, Phillips T, Zerbe A, et al. Intimate partner violence experienced by HIV-infected pregnant women in South Africa: a cross-sectional study. BMJ Open 2016;6:e011999.

27 Brown LL, Van Zyl MAR. Mitigating intimate partner violence among South African women testing HIV positive during mobile counseling and testing. AIDS Care 2018;30:65-71.

28 Conroy AA, Tsai AC, Clark GM, et al. Relationship power and sexual violence among HIV-positive women in rural Uganda. AIDS Behav 2016;20:2045-53.

29 Emusu D, Ivankova N, Jolly $\mathrm{P}$, et al. Experience of sexual violence among women in HIV discordant unions after voluntary HIV counselling and testing: a qualitative critical incident study in Uganda. AIDS Care 2009;21:1363-70.

30 Ezeanochie MC, Olagbuji BN, Ande AB, et al. Prevalence and correlates of intimate partner violence against HIV-seropositive pregnant women in a Nigerian population. Acta Obstet Gynecol Scand 2011;90:535-9.

31 Ezechi OC, Gab-Okafor C, Onwujekwe DI, et al. Intimate partner violence and correlates in pregnant HIV positive Nigerians. Arch Gynecol Obstet 2009;280:745-52.

32 Fiorentino M, Sagaon-Teyssier L, Ndiaye K, et al. Intimate partner violence against HIV-positive Cameroonian women: prevalence, associated factors and relationship with antiretroviral therapy discontinuity-results from the ANRS-12288 EVOLCam survey. Womens Health 2019;15:1745506519848546.

33 Hampanda K. Intimate partner violence against HIV-positive women is associated with Sub-Optimal infant feeding practices in Lusaka, Zambia. Matern Child Health J 2016;20:2599-606.

34 Hampanda KM, Rael CT. Hiv status disclosure among postpartum women in Zambia with varied intimate partner violence experiences. AIDS Behav 2018;22:1652-61.

35 Iliyasu Z, Abubakar IS, Babashani M, et al. Domestic violence among women living with HIV/AIDS in Kano, Northern Nigeria. Afr J Reprod Health 2011;15:41-9.

36 Malaju MT, Alene GD. Women's expectation of partner's violence on HIV disclosure for prevention of mother to child transmission of HIV in North West Ethiopia. BMC Res Notes 2013;6:96.

37 Mulrenan C, Colombini M, Howard N, et al. Exploring risk of experiencing intimate partner violence after HIV infection: a qualitative study among women with HIV attending postnatal services in Swaziland. BMJ Open 2015;5:e006907.

38 Olowookere SA, Fawole OI, Adekanle DA, et al. Patterns and correlates of intimate partner violence to women living with HIV/ AIDS in Osogbo, Southwest Nigeria. Violence Against Women 2015;21:1330-40.

39 Onu CC, Dworkin SL, Ongeri LG, et al. Brief report: sexual violence against HIV-positive women in the Nyanza region of Kenya: is condom negotiation an Instigator? J Acquir Immune Defic Syndr 2017;74:52-5.

40 Osinde MO, Kaye DK, Kakaire O. Intimate partner violence among women with HIV infection in rural Uganda: critical implications for policy and practice. BMC Womens Health 2011;11:50.

41 Wilson KS, Deya R, Masese L, et al. Prevalence and correlates of intimate partner violence in HIV-positive women engaged in transactional sex in Mombasa, Kenya. Int J STD AIDS 2016;27:1194-203.

42 Young CR, Kaida A, Kabakyenga J, et al. Prevalence and correlates of physical and sexual intimate partner violence among women living with HIV in Uganda. PLoS One 2018;13:e0202992.

43 Matseke G, Rodriguez VJ, Peltzer K, et al. Intimate partner violence among HIV positive pregnant women in South Africa. J Psychol Afr 2016;26:259-66.

44 United Nations Educational, Scientific and Cultural Organization. Addressing the links between gender-based violence and HIV in the Great Lakes region: Background information on GBV and HIV. 
Tanzania: UN Education, Scientific \& Cultural Organization, 2013. Available: http://www.unesco.org/new/fileadmin/MULTIMEDIA/HQ/ BSP/GENDER/PDF/HIVGBVbackgroundreport.pdf [Accessed $13 \mathrm{Jul}$ 2018].

45 WHO. Hiv/Aids who | regional office for Africa, 2018. Available: https://www.afro.who.int/health-topics/hivSaids [Accessed 04 Aug 2020].

46 Dwyer-Lindgren L, Cork MA, Sligar A, et al. Mapping HIV prevalence in sub-Saharan Africa between 2000 and 2017. Nature 2019;570:189-93.

47 Durevall D, Lindskog A. Intimate partner violence and HIV in ten sub-Saharan African countries: what do the demographic and health surveys tell us? Lancet Glob Health 2015;3:e34-43.

48 Orza L, Bewley S, Chung C, et al. "Violence. Enough already": findings from a global participatory survey among women living with HIV. J Int AIDS Soc 2015;18:20285.
49 CIA. Country comparison. HIV/AIDS- people living with HIV/AIDS, 2016. Available: https://www.cia.gov/library/publications/the-world factbook/rankorder/2156rank.html [Accessed 04 Aug 2020].

$50 \mathrm{CDC}$. Intersection of intimate partner violence and HIV in women, 2014. Available: https://npin.cdc.gov/publication/intersectionintimate-partner-violence-and-hiv-women [Accessed 13 Jul 2019].

51 Oringher J, Samuelson KW. Intimate partner violence and the role of masculinity in male same-sex relationships. Traumatology 2011;17:68-74.

52 Lisco CG, Leone RM, Gallagher KE, et al. "Demonstrating masculinity" via intimate partner aggression: the moderating effect of heavy episodic drinking. Sex Roles 2015;73:58-69.

$53 \mathrm{WHO}$. Strengthening health systems to respond to women subjected to intimate partner violence or sexual violence. A manual for health managers, 2017. Available: https://apps.who.int/iris/bitstream/ handle/10665/259489/9789241513005-eng.pdf 